\title{
Dropout Rate at Elementary Level in Two Primary Schools of Backward Area, Paschim Medinipur, West Bengal: A Comparative Approach
}

\author{
Mrityunjoy Jana ${ }^{1}$, Ansar Khan ${ }^{2, *}$, Soumendu Chatterjee ${ }^{3}$, Nityananda Sar ${ }^{4}$, Arosikha Das ${ }^{5}$ \\ ${ }^{1}$ Department of Education, Vinayaka Missions University, Salem, India \\ ${ }^{2}$ Department Geography and Environment Management, Vidyasagar University, Midnapore, India \\ ${ }^{3}$ Department of Geography, Presidency University, Kolkata, India \\ ${ }^{4}$ Department of Geography, Kharagpur College, Kharagpur, India \\ ${ }^{5}$ Department of Applied Geography, Ravenshaw University, Cuttack, India \\ *Corresponding author: khanansargeo@gmail.com
}

Received October 08, 2014; Revised November 02, 2014; Accepted December 31, 2014

\begin{abstract}
A dropout is considered a student who for any reason other than death leaves school before graduation without transferring to another school. Dropping out of school is a well documented social problem and often present daunting circumstances for adolescents. Dropping out is also associated with delinquency, and low school achievements. The study was conducted in two primary school of Gopiballavpur Circle (west) of Paschim Medinipur, West Bengal. For selection of 'Schools with lower primary grades only' within Gopiballavpur Circle (West), Paschim Medinipur, the list of all such schools was first arranged in ascending order on the basis of total enrolment (Grade I-IV). In case the total enrolment in a school was less than 10, it was excluded. With the help of this list, two schools (which are fells into more inaccessible and backward area than other school within circle.) were selected by circular systematic sampling method. However, we have used enrolment records collected from daily attendance book considered for study from both school. The considered data period ranges from 2003 to 2010 (seven academic sessions i.e. 2003-04, 2004-05, 2005-06, 2006-07, 2007-08, 2008-09 and 2009-10) and the data are continuous without any missing data. Reconstructed cohort method and Coefficient of Internal Efficiency are used for this study to estimates of dropout and promotion rates based on academic years and to find out important reasons of their school leaving /dropping out from school, present activity of those who are not in any school. The results of the study revealed that drop out of pupils from school in rural backward area were reluctance of parents and participation in domestic activities. Another major reason was problem of financial constraints. The parent's educational status was poor and they did not give much importance to the education of girls as they did to their sons. They perceived that sons support them in their old age.
\end{abstract}

Keywords: dropout, promotion, reconstructed cohort method, coefficient of internal efficiency

Cite This Article: Mrityunjoy Jana, Ansar Khan, Soumendu Chatterjee, Nityananda Sar, and Arosikha Das, "Dropout Rate at Elementary Level in Two Primary Schools of Backward Area, Paschim Medinipur, West Bengal: A Comparative Approach.” American Journal of Educational Research, vol. 2, no. 12 (2014): 1288-1297. doi: 10.12691/education-2-12-25.

\section{Introduction}

The phenomenon of students discontinuing studies and repeating grades before completing elementary level of education is a major impediment in achieving Universalization of Elementary Education (UEE). In order to assess its impact on achievement of UEE, it is necessary to estimate dropout and promotion rates at primary stage. At present there are two main sources of information on dropout rates (1) official statistics published annually by MHRD in Selected Educational Statistics (SES) now renamed Statistics of School Education (SSE) and (2) District Information System of Education (DISE), initially developed for District Primary
Education Programme by NIEPA (now NUEPA) and later expanded to cover all recognized schools of the country offering primary/upper primary education under Sarva Shiksha Abhiyan (SSA). Databases for both of them are the educational statistics supplied by all recognized schools of the country. In the case of DISE the schools are supposed to fill up specially designed forms and the school report card become available on to NUEPA on line.

The SSE reports dropout rates for grades 1 to 5 and grade 1 to 8 , which are actually crude estimates of the percentage of children who drop out from school between grade 1 and grade 5 and between grade 1 and grade 8 . The first is based on the ratio of the current year enrolment of grade 5 to grade 1 enrolment of 4 years back. This indicator does not take repeaters and lateral entry cases into consideration. 
DISE uses the data on enrolment and number of repeaters of two consecutive years to compute the percentage of students who dropout from primary stage of education in a year. Since some schools that supply data in one year do not supply data in the following year, the average dropout is computed on the basis of the data of common schools, that is, those which supplied data in both the years. The annual dropout rates so derived are published in DISE reports. The dropout rate thus computed does not take lateral entry cases into consideration [1].

In view of the stated limitations of both the sources, an attempt was made to modify the procedure of identification of dropouts when on behalf of Ministry of Human Resource Development (MHRD), EdCIL commissioned Development \& Research Services (DRS) to conduct a sample survey in 21 major states of the country in 200809 to assess the dropout rates at primary and upper primary stages of education. The modified procedure used in the survey is as follows.

The methodology of this survey is based on the enrolment of two consecutive years; the first one is termed as base year and the later one as successive year. Each student enrolled in a grade of a school in the base year was tracked to identify the educational status in the succeeding year. For this purpose enrolment records of the same and the next higher grade of the same school in the succeeding year and also details of students who left the school formed the basis. All the students who left school during an academic session were not treated as dropouts as some joined other schools. Educational status of such students was ascertained by making visits to their houses. Due to difference in survey methodology, estimates of the dropout rates provided by the survey were quite different from those of given by SSE and DISE. In a few states the dropout rates derived from the sample survey data were substantially less than the dropout rates from other sources. MHRD appointed a committee of experts to review dropouts among school leavers and dropout rates estimated by DRS, this committee found the procedure followed for identification of dropouts amongst school leavers and estimating dropout rates was logically sound and satisfactory. It however, suggested that a repeat (follow-up) survey in a sub-sample of schools covered by previous survey (DRS) should be conducted using the same approach and methodology to recheck the findings of previous survey. In addition to checking the results of previous survey, responsibility of providing latest two years' estimates of dropout rates was also given (from primary to upper primary) to TNS India Pvt. Limited which was selected to conduct the repeat survey or present survey. Transition rates which could not be obtained from the previous survey were also included in the scope of the present survey.

School dropout simply means early departure from school. These students, who leave their schools without completion their primary school, have no certificate. School dropout is a worldwide issue facing by education department throughout the world. India since independence is facing this problem. The most incredible element of Indian education system is its intrinsic inequalities [2,3]. A total primary enrolment rate is $57 \%$, in which an expected 7 million primary-aged children are out-of-school. According to National Educational Policy (1986), "Education is main element of economic growth because it is directly concerned with employability, entrepreneurship, women empowerment and productivity. Because it make possible the youth with enhanced ability, creative and systematically skilled to race with the fast altering Global inclination. According to the statement of the World Bank 15\% children in the age ranking of 10 to 18years, after admitting and attending school in the earlier period, dropped out before completing primary school in the academic session of 2001-02 [4]. This high percentage of dropout rate is mainly because of tedious outside of buildings, shortage of facilities and poor physical environment." Free and good environment increases opportunities for Children to teach [5].

It is not difficult to find out the main reasons of dropout there is no single factor causing dropout. But a number of factor are involved which directed it as a procedure. The main element behind this issue is poverty [6]. Poverty not only influence the demand for schooling decreases the claim for education, but also influences the incapability of family, tuition fees and other charges necessary for nourishment of children. It is linked with some high prospect expenditures of the education for the children. Distance to schools, bad quality of the education, insufficient arrangements, overloaded Grade rooms, unfit languages of the of instruction, irregularity of teacher and security problem in girls school, are common causes which increase school dropout [7]. Often drop precursors, where kids can be seen as a hazard or vulnerable to simple early withdrawal $[6,8,9]$.

Research has identified a number of reasons why children of school actually dissatisfied with schools usually, only a part of a large picture of discontent encompassing the student overall view of himself, with relation to the world [10]. Poverty along with other social factors, putting pressure on greater extent on vulnerable and study centric children to dropout [6] for example orphan, migratory kids, lower boxes/planned tribe children and minority group children of different languages, not every individual, circumstance have access distressed, are more compelling to dropout [11]. Gender weights, social performance within homes, partnerships and schools, differing pattern of approach for girl and boy [10,11,12].

Teaching different ages have different needs and sills concerning teaching methodologies and learning contents [2-13]. Children over the age of late enrolment or grade repetition, limiting older children, children in school years there is greater pressure to earn income for families [14]. Their short-term education Experience included often crowded classroom learning, limited learning opportunities Lack of learning materials and qualified teachers [5]. To make assure quality education and children capacities, progress shown through schooling system, the precedence can manipulate, that is kept on schooling within the household. Obviously those children, whose parents are educated even a little bit up to metric, are themselves more interested to keep contact school for more long [14]. Children having different age and potentials, combined together in a single classroom, without adoption of appropriate teaching methods, learning and induce to participate in the School [13].

Personal and family level factors, such as poor health, malnutrition and poverty, endangering meaningful educational opportunities for many children. As a result, many children registered in the school, but cannot participate in school. Dropout often fails to perceive any issue in 
education. The social costs of dropout problem include an under skilled labour force, lower productivity, lost taxes and increased public assistance and crime [15]. Statement of This kind of educational issues, combined with personal problems and domestic problems, such as poor health, starvation and scarcity, reduces valuable learning opportunities for students. Dropout often fails to perceive any issue in education [16,17]. The social outlay of dropout problem comprises an under practiced effort strength, lower production, mislaid taxes and increased public assistance and crime [18].

In this regards, we have achieved to study the dropout and promotion through various processed descriptive methods to find the main causes of drop out of both MADANSOL PRIMARY SCHOOL and BAITAL PARA PRIMARY SCHOOL in rural areas were reluctance of parents and participation in domestic activities. Another major reason was problem of financial constraints. The parent's educational status was poor and they did not give much importance to the education of girls as they did to their sons. They perceived that sons support them in their old age. From this table we can show the present educational status of the primary school going children in the study area. In this table we can calculate the educational status on the basis of, one student who read in different Grades.

\section{Objective of the Study}

The main objectives of the study were:

- To provide estimates of dropout and promotion rates based on academic years.

- To find out important reasons of leaving the school/dropping out from school, present activity of those who are not in any school.

\section{Materials and Methods}

\subsection{Material}

The total sample size decided to be covered under the study was two schools. The simple circular systematic procedure was used which implicitly maintained the same proportion in the subsample as that of in the sampling frame.

Table 1. School wise student enrolments at base year Grade (i.e. first academic session 2003-04)

\begin{tabular}{|c|c|c|c|c|c|c|c|c|c|c|}
\hline \multirow{2}{*}{ School } & \multirow{2}{*}{ Academic Years } & \multicolumn{2}{|c|}{ Grade-I } & \multicolumn{2}{|c|}{ Grade-II } & \multicolumn{2}{|c|}{ Grade-III } & \multicolumn{2}{|c|}{ Grade-IV } & \multirow{2}{*}{ Total } \\
\hline & & Boys & Girls & Boys & Girls & Boys & Girls & Boys & Girls & \\
\hline \multirow[b]{3}{*}{ M } & $2003-04$ & 12 & 25 & 10 & 11 & 6 & 5 & 9 & 3 & 81 \\
\hline & 2004-05 & 15 & 14 & 12 & 25 & 9 & 11 & 6 & 5 & 97 \\
\hline & 2005-06 & 15 & 19 & 15 & 14 & 12 & 24 & 9 & 11 & 119 \\
\hline \multirow[b]{2}{*}{$\mathrm{S}$} & $2006-07$ & 7 & 5 & 15 & 18 & 15 & 13 & 11 & 23 & 107 \\
\hline & 2007-08 & 11 & 13 & 7 & 5 & 13 & 17 & 14 & 13 & 93 \\
\hline \multirow{2}{*}{$\mathrm{P}$} & 2008-09 & 16 & 14 & 11 & 12 & 7 & 5 & 13 & 17 & 95 \\
\hline & 2009-10 & 20 & 17 & 16 & 13 & 11 & 12 & 7 & 5 & 101 \\
\hline \multirow[t]{6}{*}{$\mathrm{S}$} & 2010-11 & 11 & 13 & 19 & 16 & 15 & 13 & 11 & 12 & 110 \\
\hline & 2011-12 & 9 & 7 & 11 & 13 & 19 & 16 & 14 & 12 & 101 \\
\hline & 2012-13 & 17 & 11 & 9 & 7 & 11 & 12 & 18 & 15 & 100 \\
\hline & $2003-04$ & 5 & 2 & 7 & 9 & 5 & 8 & 10 & 6 & 52 \\
\hline & 2004-05 & 9 & 3 & 5 & 2 & 7 & 8 & 5 & 8 & 47 \\
\hline & 2005-06 & 7 & 8 & 9 & 2 & 5 & 2 & 7 & 8 & 48 \\
\hline \multirow[t]{2}{*}{ B } & 2006-07 & 6 & 3 & 7 & 8 & 9 & 2 & 4 & 2 & 41 \\
\hline & 2007-08 & 9 & 14 & 6 & 3 & 7 & 8 & 9 & 2 & 58 \\
\hline $\mathrm{P}$ & 2008-09 & 13 & 9 & 8 & 13 & 6 & 3 & 7 & 7 & 66 \\
\hline \multirow{4}{*}{$\mathrm{S}$} & 2009-10 & 6 & 9 & 13 & 9 & 8 & 12 & 6 & 3 & 66 \\
\hline & 2010-11 & 11 & 9 & 6 & 9 & 10 & 8 & 8 & 12 & 73 \\
\hline & 2011-12 & 10 & 8 & 10 & 9 & 6 & 9 & 10 & 8 & 70 \\
\hline & 2012-13 & 7 & 12 & 9 & 8 & 10 & 9 & 6 & 8 & 69 \\
\hline
\end{tabular}

\#MSPS-MADANSOL PRIMARY SCHOOL, @BPS-BAITAL PARA PRIMARY SCHOOL.

For selection of 'Schools with lower primary grades only' within Gopiballavpur Circle (West), Paschim Medinipur, the list of all such schools was first arranged in ascending order on the basis of total enrolment (Grade IIV). In case the total enrolment in a school was less than 10 , it was excluded. With the help of this list, two schools (which are fells into more inaccessible and backward area than other school within circle.) were selected by circular systematic sampling method.

However, we have used enrolment records collected from daily attendance book considered for study from both school. The considered data period ranges from 2003 to 2010 (seven academic sessions i.e. 2003-04, 2004-05, 2005-06, 2006-07, 2007-08, 2008-09 and 2009-10) and the data are continuous without any missing data. Those data were statistically processed and then reduced to Grade wise for further study shows in Table 1.

\subsection{Methods}

\subsubsection{Reconstructed Cohort Method}

Out of a given cohort of $N$ children entering Grade I, some children will complete Grade IV in minimum four years; some will dropout before completing Grade IV (graduating). The various indicators depicting pupils' experience as promotees and dropout are computed by using the reconstructed cohort method. It is a more pertinent and commonly used method which places less demand on the availability of detailed data over time $[19,20]$. To apply this method, data on enrolment by Grade for two consecutive years and by Grade from the first to second year will be sufficient to enable the estimation of two main flow-rates: promotion, and dropout. These rates are used in a reconstructed pupil- 
cohort flow to derive other indicators such as cohort dropout rate, average duration of the study and coefficient of internal efficiency. In the reconstructed cohort method it is assumed that the promotion and dropout rates of the base year for a specific Grade hold good for the same Grade in subsequent years. In Table 2 shows a sampled result of reconstructed cohort, which has been derived from MADANSOL PRIMARY SCHOOL (MSPS) for the academic session of 2003-04. On the way researchers have to achieve the calculation for different academic session of said schools using flow diagram on cohort analysis shown in Figure 1.

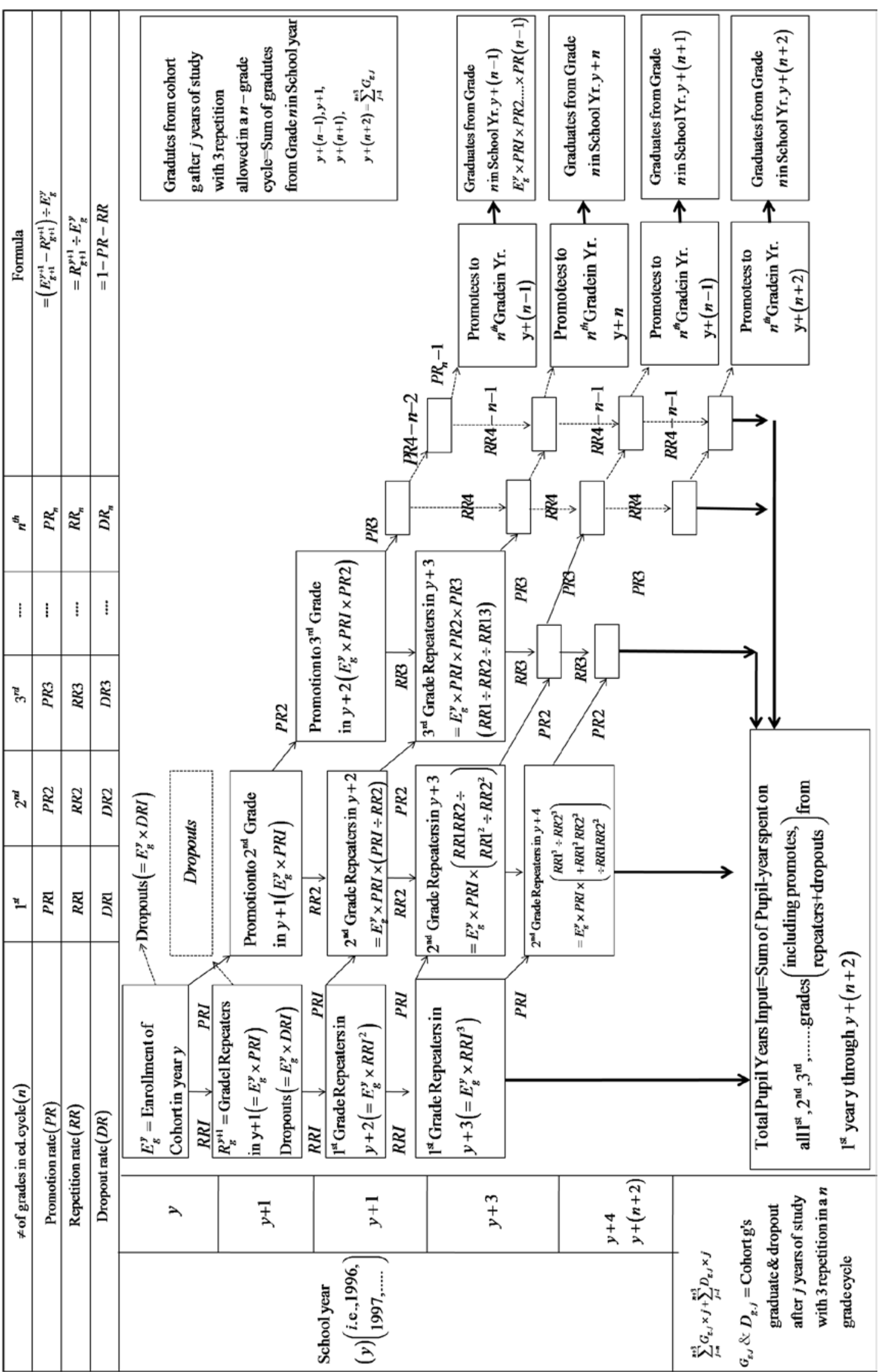

Figure 1. A flow diagram of student flow ratios of cohort $g$ using the reconstructed cohort method (Compiled from Wako (2003) and UNESCO (1998b) 
Table 2. Reconstructed cohort for the primary stage (Grade I to Grade IV) of MADANSOL PRIMARY SCHOOL (MSPS) for the academic session of 2003-04

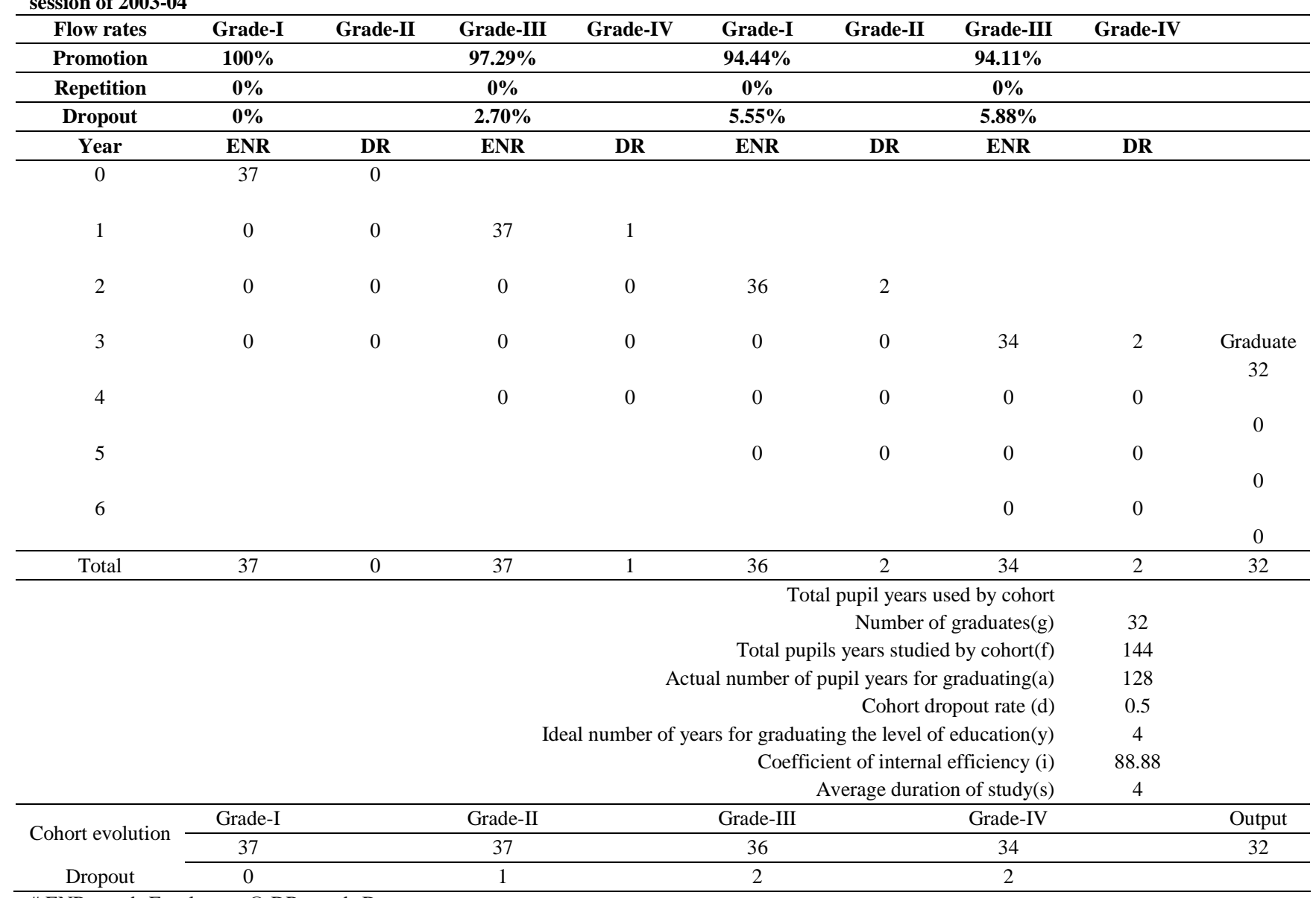

\# ENR stands Enrolment, @ DR stands Dropout.

\subsubsection{Rate of Cohort Dropout}

The children enrolled in Grade 1 of primary stage who would drop out before completing (graduating) the full cycle of primary education is the dropouts from the cohort of the corresponding level. The cohort dropout rate at primary stage is calculated as the percentage of the students of entry Grade of the primary stage to the total number of students who dropout before completing the terminal Grade of the stage.

\subsubsection{Coefficient of Internal Efficiency}

It is the ideal (optimal) number of pupil-years required (i.e. in the absence of drop-out) to produce a number of graduates from a given school-cohort for a cycle or level of education expressed as a percentage of the actual number of pupil-years spent to produce the same number of graduates. Input-Output ratio, which is the reciprocal of the coefficient of efficiency, is often used as an alternative (One school-year spent in a Grade by a pupil is counted as one pupil-year).

This is a synthetic indicator of the internal efficiency of an educational system. It summarises the consequences of drop-out on the efficiency of the educational process in producing graduates.

Divide the ideal number of pupil-years required to produce a number of graduates from a given school-cohort for the specified level of education, by the actual number of pupil-years spent to produce the same number of graduates, and multiply the result by 100 . The coefficient of internal efficiency $(i)$ is calculated on the basis of the reconstructed cohort method, which uses data on enrolment and repeaters for two consecutive years. The following formula used to determine coefficient of internal efficiency:

$$
i=\frac{\sum_{j=n}^{n+k} G_{g, j} \times n}{\left\{\sum_{j=n}^{n+k} G_{g, j} \times \mathrm{j}\right\}+\left\{\sum_{j=1}^{n+k} G_{g, j} \times \mathrm{j}\right\}} \times 100 .
$$

where,

$i$, coefficient of internal efficiency for a people cohort $g$ $G_{g, n}$, number of pupils graduating from cohort $g$ in final grade $n$ after $n$ years of study (without repetition)

$G_{g, j}$, number of pupils graduating from cohort $g$ in final grade $n$ after $j$ years of study

$D_{g, j}$, number of pupils (of the cohort $g$ ) dropping out after $j$ years of study

$k$, number of repetitions allowed

$n$, normal duration of study for a cycle or level of education

$g$, pupil-cohort

$j$, number of years of study.

A Coefficient of Efficiency approaching 100\% indicates a high overall level of internal efficiency and no wastage due to drop-out. Coefficient of Efficiency of less than $100 \%$ signals inefficiency due to Grade repetition and drop-out. As the reciprocal, the optimum input-output 
ratio is unity i.e. 1 , and inefficiency arises from any point which is greater than one.

\subsubsection{Average Duration of Study}

It provides the estimate of extra duration of completing the level of education. It is the ratio of actual pupil years for graduating $(a)$ the level of education by the graduates $(g)$.

\section{Results and Discussion}

\subsection{Promotion Rates}

The students who pass out of a Grade and join the next Grade for studies are considered as promotees. The proportion of promotes in a Grade to the total number of enrolment of that Grade is called the promotion rate for that grade. From Table 3, it is seen that there are definite increments or consisted in promotion rates from academic sessions 2003-04 to 2009-10 for MADANSOL PRIMARY SCHOOL by $0.76 \%$. Promotion rates for primary level for all the Grade I, Grade II, Grade III and Grade IV combined together have averaged is $97.59 \%$, $97.32 \%$, $96.86 \%$ and $98.62 \%$ respectively from $2003-04$ to 2009 10 in MADANSOL PRIMARY SCHOOL in one hand.
In BAITAL PARA PRIMARY SCHOOL erstwhile promotion rates for all the Grade I, Grade II, Grade III and Grade IV combined mutually have averaged is $97.57 \%$, 96.72\%, 96.05\% and $98.7 \%$ in that order from academic sessions 2003-04 to 2009-10. It is also seen that there are definite increments in promotion rates from 2003-04 to 2009-10 for BAITAL PARA PRIMARY SCHOOL by $1.91 \%$. Similar pattern was seen over the two schools for a primary grade where an increase in BAITAL PARA PRIMARY SCHOOL is around $1.15 \%$ was seen than MADANSOL PRIMARY SCHOOL by 2003-10.

At both MADANSOL PRIMARY SCHOOL and BAITAL PARA PRIMARY SCHOOL, there has been almost similar percentage increase (ranges from $96.05 \%$ to $98.7 \%$ ) in all promoted Grades by 2003-10 through intermediate seven academic sessions. It is also reveals that highest year-on-year (YOY) through intermediate academic sessions increases in promotion rates of primary was observed in MADANSOL PRIMARY SCHOOL (100\%). The following Grades shows the $100 \%$ promotion by 2003-04, 2004-05 and 2006-07 in Grade I, 2006-07, 2007-08 and 2009-10 in Grade II, 2005-06, 2006-07, 2007-08 in Grade III and 2005-06, 2006-07, 2007-08, 2008-09 and 2009-10 in Grade IV.

\begin{tabular}{|c|c|c|c|c|c|c|c|c|c|c|c|c|c|c|c|c|}
\hline \multirow{3}{*}{$\begin{array}{l}\text { Academic } \\
\text { Years }\end{array}$} & \multicolumn{4}{|c|}{ Grade (I) } & \multicolumn{4}{|c|}{ Grade (II) } & \multicolumn{4}{|c|}{ Grade (III) } & \multicolumn{4}{|c|}{ Grade (IV) } \\
\hline & \multicolumn{2}{|c|}{ MSPS } & \multicolumn{2}{|c|}{ BPS } & \multicolumn{2}{|c|}{ MSPS } & \multicolumn{2}{|c|}{ BPS } & \multicolumn{2}{|c|}{ MSPS } & \multicolumn{2}{|c|}{ BPS } & \multirow{2}{*}{$\begin{array}{c}\text { MSPS } \\
\text { D }\end{array}$} & \multicolumn{3}{|c|}{ BPS } \\
\hline & D & $\mathbf{P}$ & D & $\mathbf{P}$ & D & $\mathbf{P}$ & D & $\mathbf{P}$ & D & $\mathbf{P}$ & D & $\mathbf{P}$ & & $\mathbf{P}$ & D & $\mathbf{P}$ \\
\hline 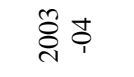 & 0 & 100 & 0 & 100 & 2.7 & 97.29 & 0 & 100 & 5.55 & 94.44 & 14.28 & 85.71 & 5.88 & 94.11 & 0 & 100 \\
\hline ঠீ & 0 & 100 & 8.33 & 91.66 & 3.44 & 96.55 & 0 & 100 & 3.57 & 96.42 & 0 & 100 & 3.7 & 96.29 & 9.09 & 90.9 \\
\hline 용 ڤ̊ & 2.9 & 97.05 & 0 & 100 & 9.09 & 90.9 & 0 & 100 & 0 & 100 & 6.66 & 93.33 & 0 & 100 & 0 & 100 \\
\hline 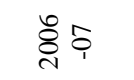 & 0 & 100 & 0 & 100 & 0 & 100 & 0 & 100 & 0 & 100 & 0 & 100 & 0 & 100 & 0 & 100 \\
\hline 용 & 4.1 & 95.83 & 8.69 & 91.3 & 0 & 100 & 4.76 & 95.23 & 0 & 100 & 0 & 100 & 0 & 100 & 0 & 100 \\
\hline$\stackrel{\infty}{\stackrel{\circ}{\circ}}$ ᄋ & 3.33 & 95.66 & 0 & 100 & 3.34 & 96.55 & 18.18 & 81.81 & 7.14 & 92.85 & 0 & 100 & 0 & 100 & 0 & 100 \\
\hline$\stackrel{\text { 용 }}{\stackrel{0}{\circ}}$ & 5.4 & 94.59 & 0 & 100 & 0 & 100 & 0 & 100 & 5.71 & 94.28 & 6.66 & 93.33 & 0 & 100 & 0 & 100 \\
\hline
\end{tabular}

\#MSPS-MADANSOL PRIMARY SCHOOL, @BPS-BAITAL PARA PRIMARY SCHOOL \$D-Dropout, ^P-Promotion.

Similarly in case of BAITAL PARA PRIMARY SCHOOL also been revealed that following Grades shows the $100 \%$ promotion by 2003-04, 2005-06,2006-07, 200809, 2009-10 in Grade I, 2003-04, 2004-05, 2005-06, 200607, 2009-10 in Grade II, 2004-05, 2006-07, 2007-08, 2008-09 in Grade III, 2003-04, 2005-06, 2006-07, 200708, 2008-09, 2009-10 in Grade IV. But in both schools have averaged $93.46 \%$ was observed in the all Grades of overall intermediate academic sessions. In some of the Grades a slight decrease in promotion rate was observes between the two academic sessions (2003-04 and 2009-10) i.e. Grade I (5.41\%) and Grade III $(0.16 \%)$. On the other hand Grade II (2.71\%) and Grade IV (5.89\%) have experienced increasing trend at MADANSOL PRIMARY SCHOOL. BAITAL PARA PRIMARY SCHOOL has experienced increasing trend at Grade III (7.62\%) and other Grades have remain not been changed. In majority of the Grades during the reference years, promotion rates for BAITAL PARA PRIMARY SCHOOL were higher than MADANSOL PRIMARY SCHOOL primary grades. The promotion rate has increased from Grade I to Grade IV both the studied schools. The promotion rate was lowest for Grade II students (90.90\%) in the year 2005-06; for Madansol Prathamik School, whereas BAITAL PARA PRIMARY SCHOOL has remained lowest for the year 2008-09 in Grade II (81.80\%).

\subsection{Dropout Rates}

The percentage of school leaver or pass-outs out of total enrolment who do not pursue studies in same or the other school during the following academic session is termed as the dropout rate. The dropout rate is different from dropout among school leavers in the sense that it is the dropout rate amongst the total enrolment and not just the school leavers. 
From Table 3, it is seen that there are definite decreases in dropout rates from academic sessions 2003-04 to 200910 for MADANSOL PRIMARY SCHOOL by $0.76 \%$. dropout rates for primary level for all the Grade I, Grade II, Grade III and Grade IV combined together have averaged is $2.25 \%, 2.65 \%, 3.14 \%$ and $1.37 \%$ respectively from 2003-04 to 2009-10 in MADANSOL PRIMARY SCHOOL in one hand.

In BAITAL PARA PRIMARY SCHOOL erstwhile dropout rates for all the Grade I, Grade II, Grade III and Grade IV combined mutually have averaged is $2.43 \%$, $3.28 \%, 3.94 \%$ and $1.29 \%$ in that order from academic sessions 2003-04 to 2009-10. It is also seen that there are definite increments in dropout rates from 2003-04 to 2009-10 for BAITAL PARA PRIMARY SCHOOL by $1.91 \%$. Similar pattern was seen over the two schools for a primary grade where a decrease in dropout at BAITAL PARA PRIMARY SCHOOL is around $1.15 \%$ was seen than MADANSOL PRIMARY SCHOOL by 2003-10.

At both MADANSOL PRIMARY SCHOOL and BAITAL PARA PRIMARY SCHOOL, there has been almost similar percentage increase (ranges from $2.06 \%$ to 2.39\%) in all dropout Grades by 2003-10 through intermediate seven academic sessions. It is also reveals that no dropout year-on-year (YOY) through intermediate academic session's increases in promotion rates of primary was observed in MADANSOL PRIMARY SCHOOL (0\%). The following Grades shows the 0\% dropout by 2003-04, 2004-05 and 2006-07 in Grade I, 2006-07, 2007-08 and 2009-10 in Grade II, 2005-06, 2006-07, 2007-08 in Grade III and 2005-06, 2006-07, 2007-08, 2008-09 and 2009-10 in Grade IV.

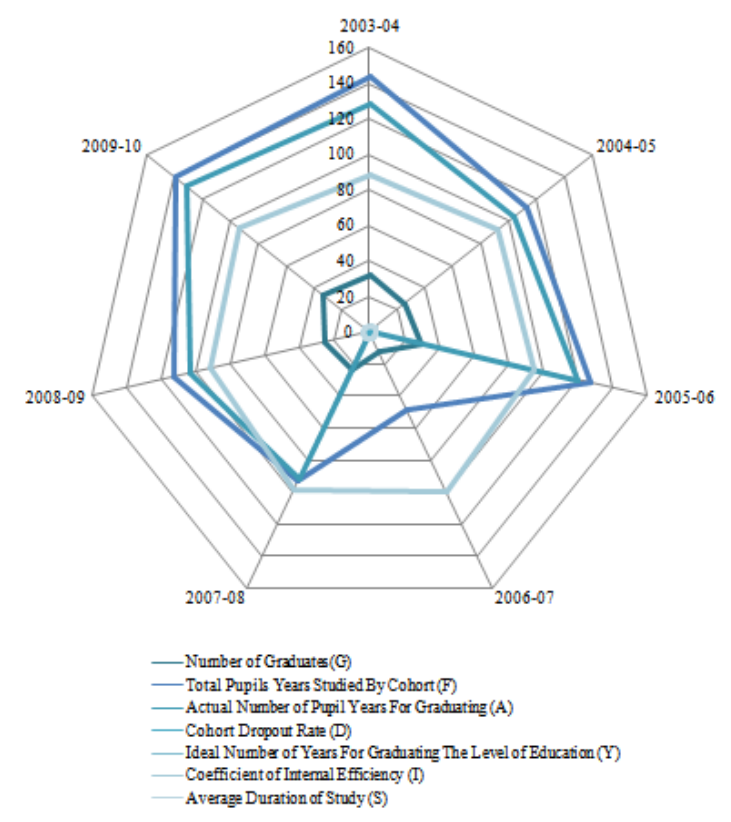

(a)
Correspondingly in case of BAITAL PARA PRIMARY SCHOOL also been revealed that following Grades shows the $0 \%$ dropout by 2003-04, 2005-06,2006-07, 2008-09, 2009-10 in Grade I, 2003-04, 2004-05, 2005-06, 2006-07, 2009-10 in Grade II, 2004-05, 2006-07, 2007-08, 2008-09 in Grade III, 2003-04, 2005-06, 2006-07, 2007-08, 200809, 2009-10 in Grade IV. But in both schools have averaged $6.54 \%$ was observed in the all Grades of overall intermediate academic sessions. In some of the Grades a slight decrease in dropout rate was observes between the two academic sessions (2003-04 and 2009-10) i.e. Grade IV $(2.18 \%)$. On the other hand Grade I (2.50\%) and Grade II $(0.64 \%)$ and in Grade III $(0.16 \%)$ have experienced increasing trend at MADANSOL PRIMARY SCHOOL.

BAITAL PARA PRIMARY SCHOOL has practised increasing trend at Grade I (0.36\%) Grade II (13.42\%) and other Grades have remain to some extent been changed. In some of the Grades a slight decrease in dropout rate was observes between the two academic sessions (2003-04 and 2009-10) i.e. Grade III (7.62). But in Grade IV has only a single dropout which encompasses in 2004-05 academic session $(9.09 \%)$.

In majority of the Grades during the reference years, dropout rates for MADANSOL PRIMARY SCHOOL were higher than BAITAL PARA PRIMARY SCHOOL grades. The dropout rate has decreased from Grade I to Grade IV both the studied schools. The dropout rate was lowest for Grade II students (2.70\% after no dropout) in the year 2003-04; for MADANSOL PRIMARY SCHOOL, whereas BAITAL PARA PRIMARY SCHOOL has remained lowest for the year 2007-08 in Grade II (4.76\%) in Figure 2.

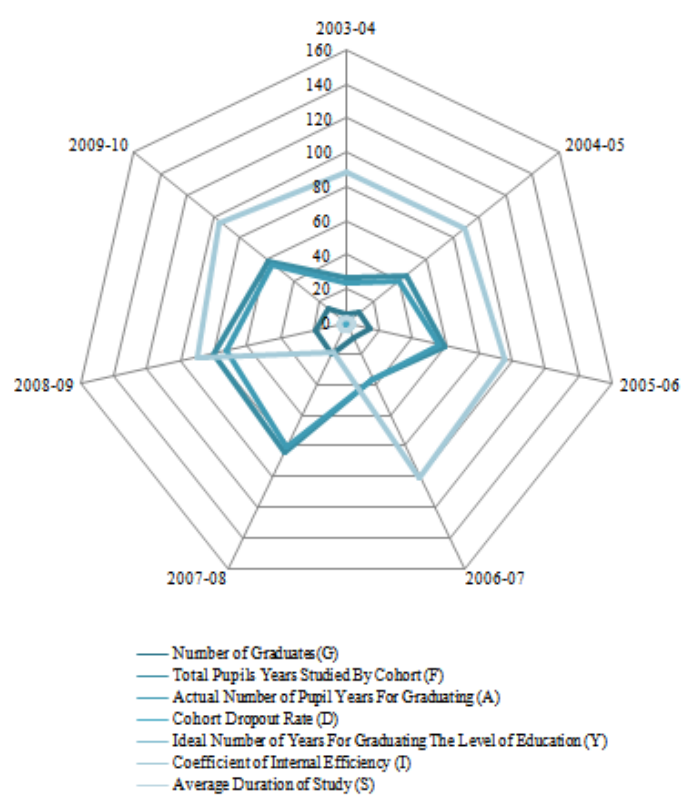

(b)

Figure 2. School and academic session wise distribution of dropout and promotion rates (a) MSPS-MADANSOL PRIMARY SCHOOL and (b) BPSBAITAL PARA PRIMARY SCHOOL

\subsection{Cohort Dropout Rate}

In order to calculate cohort dropout rates, the schoolwise education pattern has been followed for each school. Two types of cohort dropout rates have been calculated. First, for those Grades I students who discontinued studies anytime before reaching the terminal grade (Grade IV).
The rate is termed as cohort dropout rate before reaching last grade of primary. Second is the cohort dropout rate for the Grade I students who discontinued their education any time before passing the last grade of primary.

The Table 4 indicates that of the thirty seven children enrolled in Grade I during in the base year 2003, no student is dropout of Grade I, 1 of Grade II, 2 of Grade III 
and 2 of Grade IV. Thus, cohort dropout rate at primary stage in this case is $0.5 \%$. In such way we have calculated cohort dropout rate for each academic session (seven) through taken base year. The below Table 3 shows the summarised results of both schools in form of

a. Number of graduate student $(g)$

b. Total pupils-year studied by the cohort $(f)$ c. Actual no of pupils-year for graduating $(a)$

d. Ideal no of year for graduating the level of education $(y)$

e. Cohort dropout rate $(d)$

f. Co-efficient of internal efficiency $(i)$

g. Average duration of the study $(s)$.

Table 4. Reconstructed cohort parameters and their related measures for studied school (Grade I - Grade IV)

\begin{tabular}{|c|c|c|c|c|c|c|c|c|c|c|c|c|c|}
\hline \multirow{2}{*}{$\begin{array}{l}\text { Academic } \\
\text { Year }\end{array}$} & \multirow{2}{*}{$\begin{array}{c}\text { Reconstructed } \\
\text { Parameters }\end{array}$} & \multicolumn{6}{|c|}{ \#MSPS } & \multicolumn{6}{|c|}{ @BPS } \\
\hline & & Values & C-I & C-II & C-III & C-IV & OP & Values & C-I & C-II & C-III & C-IV & OP \\
\hline \multirow{9}{*}{$\begin{array}{l}\text { Oे } \\
\text { ஸे } \\
\text { ○े }\end{array}$} & $\mathrm{g}$ & 32 & & & & & & 6 & & & & & \\
\hline & $\mathrm{f}$ & 144 & & & & & & 27 & & & & & \\
\hline & $\mathrm{a}$ & 128 & & & & & & 24 & & & & & \\
\hline & $\mathrm{y}$ & 4 & & & & & & 4 & & & & & \\
\hline & d & 0.5 & & & & & & 0.1 & & & & & \\
\hline & $\mathrm{i}$ & 88.88 & & & & & & 88.89 & & & & & \\
\hline & $\mathrm{s}$ & 4 & & & & & & 4 & & & & & \\
\hline & e & & 37 & 37 & 36 & 34 & 32 & & 7 & 7 & 7 & 6 & 6 \\
\hline & $\mathrm{dr}$ & & 0 & 1 & 2 & 2 & & & 0 & 0 & 1 & 0 & \\
\hline \multirow{9}{*}{ 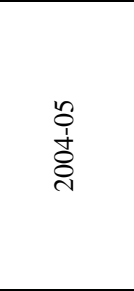 } & $\mathrm{g}$ & 26 & & & & & & 10 & & & & & \\
\hline & $\mathrm{f}$ & 113 & & & & & & 45 & & & & & \\
\hline & $\mathrm{a}$ & 104 & & & & & & 40 & & & & & \\
\hline & $\mathrm{y}$ & 4 & & & & & & 4 & & & & & \\
\hline & d & 0.3 & & & & & & 0.2 & & & & & \\
\hline & i & 92.03 & & & & & & 88.88 & & & & & \\
\hline & $\mathrm{s}$ & 4 & & & & & & 4 & & & & & \\
\hline & e & & 29 & 29 & 28 & 27 & 26 & & 12 & 11 & 11 & 11 & 10 \\
\hline & $\mathrm{dr}$ & & 0 & 1 & 1 & 1 & & & 1 & 0 & 0 & 1 & \\
\hline \multirow{9}{*}{$\begin{array}{l}8 \\
\vdots \\
\text { ஸे } \\
\stackrel{\sim}{~}\end{array}$} & $\mathrm{~g}$ & 30 & & & & & & 14 & & & & & \\
\hline & $\mathrm{f}$ & 127 & & & & & & 59 & & & & & \\
\hline & a & 120 & & & & & & 56 & & & & & \\
\hline & $\mathrm{y}$ & 4 & & & & & & 4 & & & & & \\
\hline & d & 0.4 & & & & & & 0.1 & & & & & \\
\hline & $\mathrm{i}$ & 94.48 & & & & & & 94.91 & & & & & \\
\hline & $\mathrm{s}$ & 4 & & & & & & 4 & & & & & \\
\hline & e & & 34 & 33 & 30 & 30 & 30 & & 15 & 15 & 15 & 14 & 14 \\
\hline & $\mathrm{dr}$ & & 1 & 3 & 0 & 0 & & & 0 & 0 & 1 & 0 & \\
\hline \multirow{9}{*}{ 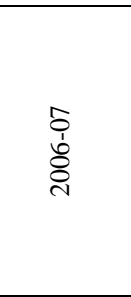 } & $\mathrm{g}$ & 12 & & & & & & 9 & & & & & \\
\hline & $\mathrm{f}$ & 48 & & & & & & 36 & & & & & \\
\hline & $\mathrm{a}$ & 48 & & & & & & 36 & & & & & \\
\hline & $\mathrm{y}$ & 4 & & & & & & 4 & & & & & \\
\hline & d & 0 & & & & & & 0 & & & & & \\
\hline & $\mathrm{i}$ & 100 & & & & & & 100 & & & & & \\
\hline & $\mathrm{s}$ & 4 & & & & & & 4 & & & & & \\
\hline & e & & 12 & 12 & 12 & 12 & 12 & & 9 & 9 & 9 & 9 & 9 \\
\hline & $\mathrm{dr}$ & & 0 & 0 & 0 & 0 & & & 0 & 0 & 0 & 0 & \\
\hline \multirow{9}{*}{$\begin{array}{l}\text { o } \\
\vdots \\
\hat{1} \\
\text { ¿े }\end{array}$} & g & 23 & & & & & & 20 & & & & & \\
\hline & $\mathrm{f}$ & 93 & & & & & & 84 & & & & & \\
\hline & $\mathrm{a}$ & 92 & & & & & & 80 & & & & & \\
\hline & $\mathrm{y}$ & 4 & & & & & & 4 & & & & & \\
\hline & d & 0.1 & & & & & & 0.3 & & & & & \\
\hline & $\mathrm{i}$ & 98.92 & & & & & & 95.23 & & & & & \\
\hline & $\mathrm{s}$ & 4 & & & & & & 4 & & & & & \\
\hline & e & & 24 & 23 & 23 & 23 & 23 & & 23 & 21 & 20 & 20 & 20 \\
\hline & $\mathrm{dr}$ & & 1 & 0 & 0 & 0 & & & 2 & 1 & 0 & 0 & \\
\hline \multirow{9}{*}{$\begin{array}{l}\text { Oे } \\
\text { oे } \\
\text { ठे }\end{array}$} & g & 26 & & & & & & 18 & & & & & \\
\hline & $\mathrm{f}$ & 113 & & & & & & 80 & & & & & \\
\hline & $\mathrm{a}$ & 104 & & & & & & 72 & & & & & \\
\hline & $\mathrm{y}$ & 4 & & & & & & 4 & & & & & \\
\hline & d & 0.2 & & & & & & 0.4 & & & & & \\
\hline & $\mathrm{i}$ & 92.03 & & & & & & 90.0 & & & & & \\
\hline & $\mathrm{s}$ & 4 & & & & & & 4 & & & & & \\
\hline & $\mathrm{e}$ & & 30 & 29 & 28 & 26 & 26 & & 22 & 22 & 18 & 18 & 18 \\
\hline & $\mathrm{dr}$ & & 1 & 1 & 0 & 0 & & & 0 & 4 & 0 & 0 & \\
\hline & $\mathrm{g}$ & 33 & & & & & & 14 & & & & & \\
\hline & $\mathrm{f}$ & 140 & & & & & & 59 & & & & & \\
\hline & $\mathrm{a}$ & 132 & & & & & & 56 & & & & & \\
\hline 으 & $\mathrm{y}$ & 4 & & & & & & 4 & & & & & \\
\hline த் & d & 0.4 & & & & & & 0.1 & & & & & \\
\hline 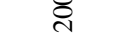 & i & 94.29 & & & & & & 94.91 & & & & & \\
\hline & s & 4 & & & & & & 4 & & & & & \\
\hline & e & & 37 & 35 & 35 & 33 & 33 & & 15 & 15 & 15 & 14 & 14 \\
\hline & $\mathrm{dr}$ & & 2 & 0 & 2 & 0 & & & 0 & 0 & 1 & 0 & \\
\hline
\end{tabular}

N:B. Number of graduate student (g), Total pupils-year studied by the cohort (f), Actual no of pupils-year for graduating (a), Ideal no of year for graduating the level of education(y), Cohort dropout rate (d), Co-efficient of internal efficiency (i), Average duration of the study (s), Cohort evolution (e), Final dropout (dr), C stands Grade, OP stands output. 


\subsection{Coefficient of Internal Efficiency}

The coefficient of internal efficiency of the system is the ratio of ideal number of pupil-years required to produce the same number of graduates to actual number of pupil-years spent to produce graduates for a cohort. The more number of years taken to pass out less is the internal efficiency. It summarises the consequences of dropout on the efficiency of the educational process in producing graduate. It is calculated by taking the ratio of the ideal no. of pupil years required for a student to graduate and average number of pupil years that are invested on a graduate.

As presented in Table 4, overall level, the coefficient of internal efficiency for 2003-2004 to 2009-10 was averaged estimated at $93.82 \%$ for two schools. The MADANSOL PRIMARY SCHOOL with high coefficients of internal efficiency at the primary stage in 2006-07 was $100 \%$ and followed by $98.92 \%$ (2007-08), 94.48\% (2005-06), 94.29\% (2009-10) 92.03\% (2004-05 and 2008-09) and $88.88 \%$ (2003-04) and the lower coefficients of internal efficiency (88.88\%) at the primary stage was to be found in 2003-04 also. Moreover, BAITAL PARA PRIMARY SCHOOL with high coefficients of internal efficiency at the primary stage in 2006-07 was $100 \%$ and followed by $95.23 \%$ (2007-08), 94.91\% (2005-06 and 2009-10), 94.48\% (2005-06), 94.29\% (2009-10) 92.03\% (2004-05 and 2008-09) and 88.89\% (2003-04) and the lower coefficients of internal efficiency $(88.88 \%)$ at the primary stage was to be found in 2004-05 also.

\subsection{Average Duration of Study at Primary Stage}

The average duration of study has also been calculated separately for primary and elementary stages for both the assessment years i.e. 2003-04 to 2009-10.The average duration of study at primary stage in 2003-04 to 2009-10 for all Grades combined together was 4 years in Table 4 .

\section{Conclusion}

Depending upon availability of data, an indicator to measure drop-out rate should be developed. If resources available, true-cohort study where each and every enrolled child is tracked should be undertaken which can be used for both assessing drop-out as well as completion rate. If resources are not available and data available, retention rate by using enrolment and repeaters data over a period of five years should only be utilized to assess retaining capacity of an education system. The retention rate so obtained is subtracted from 100 to obtain drop-out rate at an educational level. To know real cause of low retention/high drop-out rate, it is essential that the same be calculated and analysed at disaggregated levels and if data available, separately for boys and girls, rural and urban areas and for SC and ST children.

The root cause of high drop-outs can be identified by calculating grade-to-grade flow rates such as, promotion, drop-out and repetition rate. This will help a district/state in identifying in which grade there is high incidence of drop-out and repetition and also in knowing whether the same is because of boys/girls SC/ST children. The gradeto-grade drop-out rates can also be used in assessing average drop-out and repetition during intermediary year. The average indicate quantum of drop-out during intermediary year in relation to total enrolment in primary grades. Average drop-out rate can also be used to examine trends in drop-out and repetition rate over a period of time but the same is different than the retention rate which is based upon enrolment data over a period of five years where as average drop-out rate is simply based upon enrolment and repeaters data of only two years. As has been demonstrated in this note, grade-to-grade transition rates can also be used to do construct indicators of internal efficiency of education system.

By just quantifying drop-out rate, the situation will not improve automatically for that purpose the first major exercise is to know reasons of low promotion and high drop-out and repetition. This should necessarily follow by reason and area specific strategies without which no improvement is expected. This should form part of Annual Work Plan and Budget under SSA and the Project Approval Board should rigorously monitor it. Year 2010 is approaching fast and we cannot sit hoping that situation (with regard to drop-out) will improve automatically. Still we have more than four years to more optimally and rigorously utilize provisions made under SSA to work towards achieving universal elementary education. The following Effective Measures to Tackle Drop-out as follows:

- Most of the parents of this district are below the poverty line. The government must give scholarship to the poor students in greater number and control the price and quality of copies and other stationeries, school uniform and shoes, so that common man can easily afford these necessities for their children's.

- Efforts should be made to encourage wealthy and influential people of the society to provide financial assistance to the poor and needy students to continue and complete their education. In addition to this the community must keep itself in touch with schools, so that their problems and difficulties are sorted out.

- This is also recommended that government should investigate the parents to give proper attention to their children. It is also the prior duty of the government to inform the parents about the value and importance of education through mass media like TV, Radio, Newspaper, and magazines.

- It is also suggested that the government should provide basic facilities like drinking water, electricity, toilet, sitting -mats, furniture, and black boards on priority bases.

- Educational awareness programs should be introduced for adults.

- Co-curricular activities must be started in high schools on large scale to engage the attention of the students in their daily programs.

- The government should start some religious education programs at secondary school level for the spiritual development of the students.

- The curriculum should be designed according to the actual needs of the society.

- Vigorous change should be brought into curriculum and in the method of teaching. Children from 
agricultural background and environment should be given practical opportunities for gardening and farming in the school.

- Our present educational system is mostly theoretical emphasizing rote memorization. Govt should introduce activity based curriculum and should discourage rote memorization. Activity method should be made compulsory the development of an inquiring mind, a liking for manual and technical work.

- The government should start teacher welfare programmes to reduce the problems of the teachers in this way the teacher would be able to give due attention to their duties and students.

- Government must setup industries to minimize the problem of unemployment of educated persons.

\section{Acknowledgement}

We would like to express our gratitude to the students of both schools for providing us valuable information on various socio-economic aspects of dropout. For this work we would also indebt to the Head Master of both Primary schools for helping in collecting quantative and qualitative data. We would express our gratitude to all whose names have not been mentioned individually but have helped us in this work.

\section{References}

[1] Punelekar, S.P.. School Drop-out among Harijan Children, Causes \& Cure, Central Institute of Research \& Training in Public Cooperation, New Delhi 1975. 1975.

[2] Shah M.R. A study of incidence and factors responsible for dropping out of children from municipal and local authority schools in Greater Bombay and Thana Districts from standard I to VIII during the last four year i.e. 1973, 1974, 1977, 1983 (NCBRT, Finance). 1983.

[3] R. Pandya and S. Bora. A Study of Factors Causing School Dropout, Journal of Indian Education, November, pp. 32-37. 1997.

[4] Sengupta, P and J Guha. Enrolment Dropout and Grade Completion of Girl Children in West Bengal, Economic and Political Weekly, 37(17), April 27, pp 1621-37. 2002.
[5] Alexander, R. Education for All, the Quality Imperative and the Problem of Pedagogy. CREATE Pathways to Access No 20. Consortium for Research on educational Access, Transitions and Equity: University of Sussex. 2008.

[6] Jimerson, S, B Egeland, A Sroufe and B Carlson. A Prospective Longitudinal Study of High School Dropouts Examining Multiple Predictors across Development, Journal of School Psychology, 38(6), pp 525-49. 2002.

[7] Colclough, C., Rose, P. and Tembon, M.. Gender Inequalities in Primary Schooling: The Roles of Poverty and Adverse Cultural Practice. International Journal of Educational Development, 20: 527. 2000.

[8] Lewin, K.M.. Access, Age and Grade. CREATE Policy Brief No 2. Consortiu for Research on Edwww.qurtuba.edu.pk/ucational Access, Transitions and Equity: University of Sussex. 2008.

[9] Ampiah G.J. and Adu-Yeboah, C.. Mapping the incidence of school dropout: case study of communities in Northern Ghana Comparative Education, vol. 45 Issue 2, pp 219-232. 2009.

[10] Lloyd, C.B., Mete, C. and Grant, M.J. The implications of changing educational and family circumstances for children's grade progression in rural Pakistan: 1997-2004. 2009.

[11] UNESCO. EFA Global Monitoring Report 2010: Reaching the Marginalized. Paris: UNESCO Publishing. 2010.

[12] Leach, F., Fiscian, V., Kadzamira, E., Lemani., E. and Machakanja, P. An Investigative Study of the Abuse of Girls in African Schools. London: DFID. 2003.

[13] Mathur J.S., Jain S.P. \& Rahim C.A. Rural youth from Primary Groups, Dropouts and Non-students, A study of four state NIRD. 1987.

[14] Lloyd, C.B., Mete, C. and Grant, M.J. The implications of changing educational and family circumstances for children's grade progression in rural Pakistan: 1997-2004. Economics of Education Review, 28(1): 152-160. 2009.

[15] Keng, Chansopheak. Household Determinants of Schooling Progression among Rural Children in Cambodia, International Education Journal, 5(4), pp 552-61. 2004.

[16] Aggarwal, Yash. How Many Pupils Primary Education in Five Years, National Institute of Educational Planning and Administration (NIEPA), New Delhi. 2000.

[17] Borooah, Vani K. Births Infants and Education: An Econometric Portrait of Women and Children in India, Development and Change, 34, pp 67-102. 2003.

[18] Arif, G.M. and Najum, U.S. Production of Cognitive and Life Skills in Public, Private, and NGO Schools in Pakistan. Pakistan Development Review (PDR), 42: 1 Spring. Pp. 1-28. 2003.

[19] Wako, T. N. Basic indicators of education systems' performance. Harare, Zimbabwe: Fontline Electronic. 2003.

[20] UNESCO. Use of cohort analysis models for assessing educational internal efficiency. Retrieved January 21, 2007, from http:// www.uis.unesco.org/i_pages/indspec/cohorte.htm. 1998b. 